\title{
The puzzle of genetics in Brugada syndrome: a disease with a high risk of sudden cardiac death in young people
}

\author{
Ching-Yu Julius Chen ${ }^{1}$, Eric Y. Chuang ${ }^{2,3}$ \\ ${ }^{1}$ Cardiovascular Center and Division of Cardiology, Department of Internal Medicine, National Taiwan University Hospital and National Taiwan \\ University College of Medicine, Taipei, Taiwan; ${ }^{2}$ Graduate Institute of Biomedical Electronics and Bioinformatics, National Taiwan University, \\ Taiwan; ${ }^{3}$ Bioinformatics and Biostatistics Core, Center of Genomic and Precision Medicine, National Taiwan University, Taiwan \\ Correspondence to: Eric Y. Chuang, ScD, EMBA. Graduate Institute of Biomedical Electronics and Bioinformatics, National Taiwan University, No. 1, \\ Sec. 4, Roosevelt Rd., Taipei 106, Taiwan. Email: twinkle6912@outlook.com; chuangey@ntu.edu.tw.
}

Submitted Jul 30, 2020. Accepted for publication Aug 21, 2020.

doi: 10.21037/apm-20-1510

View this article at: http://dx.doi.org/10.21037/apm-20-1510

Brugada syndrome $(\mathrm{BrS})$ is an arrhythmia syndrome that carries a high risk of death for sufferers. First reported by Brugada et al. in 1992, BrS is as an inherited cardiac disorder characterized by a distinct electrocardiogram (ECG) pattern. BrS mainly affects young people, with the average age at diagnosis being $40 \pm 22$ years, and males (1-3), although some old and female BrS patients have also been reported (4-6).

Since $1^{\text {st }}$ diagnostic criteria of $\mathrm{BrS}$ was published in 2002, the diagnostic criteria for $\mathrm{BrS}$ have changed over time (7-11). $\mathrm{BrS}$ is currently diagnosed when ST-segment elevation showing type 1 morphology $\geq 2 \mathrm{~mm}$ in $\geq 1$ lead among the leads $\mathrm{V} 1$ or $\mathrm{V} 2$ positioned in the $2^{\text {nd }}, 3^{\text {rd }}$, or $4^{\text {th }}$ intercostal space in 12-lead electrocardiogram, appears spontaneously or after a provocative drug test with administration of class I antiarrhythmic drugs and an assessment of the patient's clinical presentations and genetic mutations (10).

Many clinical conditions, including neuromuscular diseases, electrolyte imbalance or alcohol intoxication, may elicit the ECG patterns of $\mathrm{BrS}$; such cases are referred to as acquired BrS or Brugada phenocopy (12-14). Provocative pharmacological testing with class I sodium channel blockers can be used to differentiate congenital $\mathrm{BrS}$ from acquired BrS. Because genetic testing is recommended only for congenital $\mathrm{BrS}$, acquired $\mathrm{BrS}$ must be ruled out before a diagnosis of true congenital $\mathrm{BrS}$ is made.

Although some studies have reported that $\mathrm{BrS}$ is an inherited disorder that is mostly autosomal dominant and displays incomplete penetrance, many sporadic BrS cases have been recorded. Priori et al. reported that the overall disease penetrance in 4 small $\mathrm{BrS}$ families with mutations in the SCN5A gene was $16 \%$ (range, $12.5 \%$ to $50 \%$ ) (15). The gene SCN5A encodes $\alpha$ subunits of the human major cardiac sodium channel (Nav1.5), and it was reported as the first BrS-causal gene in 1998. Defects in the genes encoding for calcium channels and potassium channels have also been linked with BrS phenotype. After two decades, variants in several susceptibility genes have been identified in Sodium Voltage-Gated Channel Alpha Subunit 5 (SCN5A), calcium voltage-gated channel subunit alpha1 C (CACNA1C), calcium channel, voltage-dependent, beta 2 (CACNB2), calcium voltage-gated channel auxiliary subunit alpha2delta 1(CACNA2D1), glycerol-3-phosphate dehydrogenase 1 like $(G P D 1 L)$, sodium channel beta-1 subunit $(S C N 1 B)$, sodium voltage-gated channel beta subunit 2 (SCN2B), sodium voltage-gated channel beta subunit $3(S C N 3 B)$, potassium voltage-gated channel subfamily $\mathrm{D}$ member 3 (KCND3), potassium voltage-gated channel subfamily E member 3 (KCNE3), potassium voltage-gated channel subfamily $\mathrm{D}$ member 5 (KCNE5), potassium voltage-gated channel subfamily J member 8 (KCN78), Sodium VoltageGated Channel Alpha Subunit 10 (SCN10A), RAN Guanine Nucleotide Release Factor (RANGRF), plakophilin-2 $(P K P 2)$, potassium voltage-gated channel subfamily B member 2 (KCNB2), and Hairy/enhancer-of-split related with YRPW motif protein 2 (HEY2), accounting for less than $30 \%$ of $\mathrm{BrS}$ cases $(3,16,17)$. However, in approximately $70 \%$ of BrS patients, the genes that caused their disease are unknown.

Large geographic differences have been reported, not 
only in the prevalence of $\mathrm{BrS}$ in the community-based or hospital-based populations, but also in the prevalence of ECG abnormalities and genetic mutations among BrS patients. BrS is generally believed to occur more frequently in Southeast Asia (estimated prevalence: 12:10,000) than in Western countries (estimated prevalence: $1-5: 10,000$ ) $(3,18)$. A pooled analysis of the community- and hospitalbased population studies on $\mathrm{BrS}$ worldwide showed that the prevalence of Brugada type 1 ECG pattern is higher in Asia than in Europe or the United States; similarly, the prevalence of Brugada type 2/3 ECG pattern is also higher in Asia than in Europe or the United States (19). Furthermore, geographic differences in genetic susceptibility to mutations in SCN5A have also been described: $20-25 \%$ of $\mathrm{BrS}$ cases presented with SCN5A mutations in Caucasian populations (20,21), compared with $11-14 \%$ in Japanese populations, and $<10 \%$ in the Han Chinese population in Taiwan (22). The prevalence of certain $S C N 5 A$ promoter polymorphisms in a haplotype variant was fairly higher in Asians. This variants could reduce transcriptional activity in vitro, and modulate variability in cardiac conduction as assessed by $\mathrm{PR}$ and $\mathrm{QRS}$ durations (23). A recent report suggested that some singlenucleotide polymorphisms (SNPs) associated with BrS or electrocardiogram traits exist across various populations. The cumulative risk of BrS-related SNPs in Han Chinese $\mathrm{BrS}$ patients is similar to that in Caucasian BrS patients; however, the risk appears to be correlated with the absence of SCN5A mutations $(24,25)$. This finding suggested that the disposition of disease-causal genes among $\mathrm{BrS}$ patients in the Asian populations might partly differ from that in the Caucasian population.

As disease penetrance for $\mathrm{BrS}$ is incomplete and agerelated, genetic testing may be used for diagnosis and for the screening of at-risk family members. In 2013, the Heart Rhythm Society (HRS)/European Heart Rhythm Association (EHRA)/Asia-Pacific Heart Rhythm Society (APHRS) expert consensus stated that comprehensive or BrS1 (SCN5A)-targeted genetic testing could be useful for patients for whom a cardiologist has established a clinical index of suspicion for BrS based on the patient's clinical history, family history, and the resting surface 12-lead ECGs and/or provocative drug challenge testing) (9). To date, over 20 genes have been reported to be associated with $\mathrm{BrS}$ and are routinely tested as single-gene causes for this condition on a variety of clinical genetic testing panels worldwide. Hosseini et al.'s evidence-based review of genes reported to cause $\mathrm{BrS}$ and routinely clinically tested in patients indicated that 20 of 21 genes lacked sufficient genetic evidence to support their causality for BrS (26). Furthermore, ancestral differences also impact the interpretation of classification of pathogenicity of variants identified from BrS patients (27). The causality of $\mathrm{BrS}$-associated genes is much disputed; many of these genes demand further research but may be clinically validated in the future.

Although controversies still exist, more than two decades of extensive research in BrS has helped physicians and researchers to gain a better understanding of the overall spectrum of the condition, including its molecular pathophysiology, genetic background, and disease management. Sanger sequencing, which was considered as the gold standard technology for DNA sequencing, was applied for the mutation screening of $\mathrm{BrS}$ (28). However, recent years have seen the development of new technologies that provide high-throughput screening, such as microarrays, whole-exome sequencing, and wholegenome sequencing, which are able to identify a variant at a single nucleotide resolution in relatively medium- to large-sized genomic regions. These technological genomic advancements enable the detection of genetic variations in patients, with high accuracy and reduced cost (24,29-32). Therefore, it is only a matter of time before the puzzle of genetics in $\mathrm{BrS}$ is solved.

\section{Acknowledgments}

Funding: None.

\section{Footnote}

Provenance and Peer Review: This article was a free submission to the journal. The article did not undergo external peer review.

Conflicts of Interest: Both authors have completed the ICMJE uniform disclosure form (available at http://dx.doi. org/10.21037/apm-20-1510). The authors have no conflicts of interest to declare.

Ethical Statement: The authors are accountable for all aspects of the work in ensuring that questions related to the accuracy or integrity of any part of the work are appropriately investigated and resolved.

Open Access Statement: This is an Open Access article distributed in accordance with the Creative Commons 
Attribution-NonCommercial-NoDerivs 4.0 International License (CC BY-NC-ND 4.0), which permits the noncommercial replication and distribution of the article with the strict proviso that no changes or edits are made and the original work is properly cited (including links to both the formal publication through the relevant DOI and the license). See: https://creativecommons.org/licenses/by-nc-nd/4.0/.

\section{References}

1. Juang JM, Huang SK, Tsai CT, et al. Characteristics of Chinese patients with symptomatic Brugada syndrome in Taiwan. Cardiology 2003;99:182-9.

2. Michowitz Y, Milman A, Andorin A, et al. Characterization and Management of Arrhythmic Events in Young Patients With Brugada Syndrome. J Am Coll Cardiol 2019;73:1756-65.

3. Mizusawa Y, Wilde AA. Brugada syndrome. Circ Arrhythm Electrophysiol 2012;5:606-16.

4. Juang JM, Lai LP, Lin JL et al. Brugada syndrome in the elderly in Taiwan-Report of two cases. Acta Cardiologica Sinica 2005;21:62-7.

5. Chen CJ, Juang JJ, Lin LY, et al. Gender Difference in Clinical and Genetic Characteristics of Brugada Syndrome: SADS-TW BrS Registry. QJM 2019;112:343-50.

6. Milman A, Gourraud JB, Andorin A, et al. Gender differences in patients with Brugada syndrome and arrhythmic events: Data from a survey on arrhythmic events in 678 patients. Heart Rhythm 2018;15:1457-65.

7. Wilde AA, Antzelevitch C, Borggrefe M, et al. Proposed diagnostic criteria for the Brugada syndrome: consensus report. Circulation 2002;106:2514-9.

8. Antzelevitch C, Brugada P, Borggrefe M, et al. Brugada syndrome: report of the second consensus conference: endorsed by the Heart Rhythm Society and the European Heart Rhythm Association. Circulation 2005;111:659-70.

9. Priori SG, Wilde AA, Horie M, et al. Executive summary: HRS/EHRA/APHRS expert consensus statement on the diagnosis and management of patients with inherited primary arrhythmia syndromes. Europace 2013;15:1389-406.

10. Antzelevitch C, Yan GX, Ackerman MJ, et al. J-Wave syndromes expert consensus conference report: Emerging concepts and gaps in knowledge. J Arrhythm 2016;32:315-39.

11. Chen CJ, Juang JJ, Chen YH, et al. Comparisons of clinical impacts on individuals with Brugada electrocardiographic patterns defined by ISHNE criteria or EHRA/HRS/
APHRS criteria: a nationwide community-based study. Ann Med 2018;50:7-15.

12. Wang JG, McIntyre WF, Kong W, et al. Electrocutioninduced Brugada phenocopy. Int J Cardiol 2012;160:e35-7.

13. Shimizu W. Acquired forms of the Brugada syndrome. J Electrocardiol 2005;38:22-5.

14. Freyermuth F, Rau F, Kokunai Y, et al. Splicing misregulation of SCN5A contributes to cardiac-conduction delay and heart arrhythmia in myotonic dystrophy. Nat Commun 2016;7:11067.

15. Priori SG, Napolitano C, Gasparini M, et al. Clinical and genetic heterogeneity of right bundle branch block and ST-segment elevation syndrome: A prospective evaluation of 52 families. Circulation 2000;102:2509-15.

16. Crotti L, Marcou CA, Tester DJ, et al. Spectrum and prevalence of mutations involving BrS1- through BrS12-susceptibility genes in a cohort of unrelated patients referred for Brugada syndrome genetic testing: implications for genetic testing. J Am Coll Cardiol 2012;60:1410-8.

17. Juang JJ, Horie M. Genetics of Brugada syndrome. J Arrhythm 2016;32:418-25.

18. Berne P, Brugada J. Brugada syndrome 2012. Circ J 2012;76:1563-71

19. Juang JM, Chen CY, Chen YH, et al. Prevalence and prognosis of Brugada electrocardiogram patterns in an elderly Han Chinese population: a nation-wide community-based study (HALST cohort). Europace 2015;17 Suppl 2:ii54-62.

20. Chen Q, Kirsch GE, Zhang D, et al. Genetic basis and molecular mechanism for idiopathic ventricular fibrillation. Nature 1998;392:293-6.

21. Alings $M$, Wilde A. "Brugada" syndrome: clinical data and suggested pathophysiological mechanism. Circulation 1999;99:666-73.

22. Juang JM, Tsai CT, Lin LY, et al. Unique clinical characteristics and SCN5A mutations in patients with Brugada syndrome in Taiwan. J Formos Med Assoc 2015;114:620-6.

23. Bezzina CR, Shimizu W, Yang P, et al. Common sodium channel promoter haplotype in asian subjects underlies variability in cardiac conduction. Circulation 2006;113:338-44.

24. Juang JJ, Liu YB, Chen CJ, et al. Validation and Disease Risk Assessment of Previously Reported Genome-Wide Genetic Variants Associated with Brugada Syndrome: SADS-TW BrS Registry. Circ Genom Precis Med 2020;13:e002797. 
25. Bezzina CR, Barc J, Mizusawa Y, et al. Common variants at SCN5A-SCN10A and HEY2 are associated with Brugada syndrome, a rare disease with high risk of sudden cardiac death. Nat Genet 2013;45:1044-9.

26. Hosseini SM, Kim R, Udupa S, et al. Reappraisal of Reported Genes for Sudden Arrhythmic Death: An Evidence-Based Evaluation of Gene Validity for Brugada Syndrome. Circulation 2018;138:1195-205.

27. Chen CJ, Lu TP, Lin LY, et al. Impact of Ancestral Differences and Reassessment of the Classification of Previously Reported Pathogenic Variants in Patients With Brugada Syndrome in the Genomic Era: A SADS-TW BrS Registry. Front Genet 2018;9:680.

28. Sanger F, Nicklen S, Coulson AR. DNA sequencing with chain-terminating inhibitors. Proc Natl Acad Sci U S A 1977;74:5463-7.

29. Juang JM, Lu TP, Lai LC, et al. Disease-targeted

Cite this article as: Chen CYJ, Chuang EY. The puzzle of genetics in Brugada syndrome: a disease with a high risk of sudden cardiac death in young people. Ann Palliat Med 2020;9(6):4394-4397. doi: 10.21037/apm-20-1510 sequencing of ion channel genes identifies de novo mutations in patients with non-familial Brugada syndrome. Sci Rep 2014;4:6733.

30. Cordova-Fletes C, Rangel-Sosa MM, Martinez-Jacobo LA, et al. Whole-exome sequencing in three children with sporadic Blau syndrome, one of them co-presenting with recurrent polyserositis. Autoimmunity 2020;53:344-52.

31. Dou J, Wu D, Ding L, et al. Using off-target data from whole-exome sequencing to improve genotyping accuracy, association analysis and polygenic risk prediction. Brief Bioinform 2020. [Epub ahead of print].

32. Hu X, Guo R, Guo J, et al. Parallel Tests of Whole Exome Sequencing and Copy Number Variant Sequencing Increase the Diagnosis Yields of Rare Pediatric Disorders. Front Genet 2020;11:473.

(English Language Editor: J. Reynolds) 